\section{ADSORPTIVE INTERACTIONS BETWEEN Membranes and Trace Contaminants}

L.D. Nghiem, A.I. Schäfer, T.D.Waite

Centre for Water \& Waste Technology

School of Civil \& Environmental Engineering, UNSW

Sydney NSW 2052

$\mathrm{Ph} 0293854470$

Fax 0293856139

Email A.Schaefer@unsw.edu.au

ABSTRACT: Widespread occurrences of endocrine-disrupting chemicals (EDCs) in waterways have attracted a great attention of the scientific community. While scientific evidence associated with human health is restricted due to the long-term effects, impacts evidence associated with human health is restricted due to the long-term effects, impacts
of EDCs on trout at the common concentration encountered in sewage effluent have been of EDCs on trout at the common concentration encountered in sewage effluent have been
confirmed by both in vitro and in vivo studies. The impacts of steroid estrogens such as confirmed by both in vitro and in vivo studies. The impacts of steroid estrogens such as
estrone, estradiol (natural hormones) and ethinylestradiol (a synthetic hormone) are often more serious than other synthetic EDCs as they have far higher endocrine-disrupting potency, despite of their low concentration.

This paper investigates retention and adsorptive behavior of the natural hormones estrone by two commercial reverse osmosis membranes TFC-S and X-20, using dead end stirred cell systems. While an adsorptive process that reaches a breakthrough governs the retention of estrone by the TFC-S membrane; a sieving mechanism is responsible for the high removal of estrone using the $\mathrm{X}-20$ membrane.

Keywords

Endocrine disrupters, hormones, nanofiltration, adsorption, water and wastewater treatment.

\section{INTRODUCTION}

In vitro and in vivo studies by many researchers have confirmed the impacts of endocrinedisrupting chemicals (EDCs) on trout at the common concentration encountered in sewage effluent. Amongst many types of EDCs the impacts of steroid estrogens such as estrone, effluent. Amongst many types of EDCs the impacts of steroid estrogens such as estrone,
estradiol (natural hormones) and ethinylestradiol (a synthetic hormone) are prominent as they have far higher endocrine-disrupting potency than other synthetic EDCs (Johnson and Stumpter, 2001; Ternes et al., 1999a and 1999b). In spite of the magnitude of this problem, research on the removal of EDCs in water and wastewater treatment remains to date very limited due to their relatively low concentration and the associated analytical difficulties.

Advanced treatment technologies are required for more stringent requirements in water and wastewater treatment. Membrane processes have been widely accepted of being able to comply with such standards. As performance of conventional wastewater treatment of different plants on removal of steroid estrogens varies greatly and, concentrations of some steroid estrogens in secondary effluent are still able enough to harm wildlife such as fish in particular (Johnson and Stumpter, 2001), reverse osmosis process is likely to play an important role in removal of these compounds. Retention of organic compounds by reverse osmosis membranes has been the subject of considerable research. Molecular weight of organic solutes and salt retention of the membranes may be a poor predictor of the retention (Wiesner and Buckley, 1996; Schaefer et al, 2001). Indeed, retention of organic solutes by RO membranes can be governed by a complex fashion on the chemistry of the solute-membrane interactions. Solute and solvent transport across the membrane can often be described in term of their affinity to the membrane material and membrane can often be described in term of their affinity to the membrane material and
their diffusive transport within the membrane. It has been observed that compounds that are capable of significant hydrogen bonding tend to be removed to a lesser extent (Wiesner and Buckley, 1996).

Several researchers have shown that nanofiltration and reverse osmosis processes is capable of removing trace organics including natural hormones and a wide range of pesticides (Kiso et al, 2001; Schäfer et al, 2001; Kiso et al, 2000). In our previous work, removal of the trace contaminant estrone using eight different nanofiltration and reverse osmosis membranes, which cover a wide pore size range, has been studied. It was found that estrone could be adsorbed to the surface of some membranes and subsequently give the impression of high retention. This adsorptive phenomenon is of concern as it may result in contaminants leakage or bulk release when desorption occurs. This paper investigates retention and adsorptive behavior of the natural hormones estrone on two $\mathrm{RO}$ investigates retention and adsorptive behavior of the natural hormones estrone on two RO membranes TFC-S and X-20.

\section{Materials And Methods}

\subsection{Membranes}

Two reverse osmosis membranes TFC-S and X-20 were selected for this study due to their excellent salt retention of more than $99 \%$ as specified by the manufacturers. The former was supplied by Fluid System (San Diego, USA) and the latter was supplied by Trisep Corporation (Goleta, USA). Membrane material and pure water flux at 5 bar are summarised in Table 1. Assuming that the active layer thickness is the same, TFC-S is expected to have a larger pore size as

Table 1: Membrane types and pure water flux

\begin{tabular}{cccc}
\hline Membrane Type & $\left.\begin{array}{c}\text { Average Pure Water } \\
\text { Flux }\end{array} \mathrm{Lm}^{-2} \mathrm{~h}^{-1}\right]$ & $\begin{array}{c}\text { Membrane } \\
\text { resistance }\left[\mathrm{m}^{-1}\right]\end{array}$ & Membrane material \\
\hline TFC-S & $55.0 \pm 7.3$ & $3.3 \cdot 10^{13}$ & Polyamide on Polysulfon support \\
X-20 & $20.5 \pm 2.4$ & $8.8 \cdot 10^{13}$ & Polyamide-urea Composite \\
\hline
\end{tabular}

* Average values are derived from all experiments and variations are averaged.

2.2 Filtration System and Protocol

Experiments were carried out in a $185 \mathrm{~mL}$ stainless steel stirred cell. Details of the filtration system were described elsewhere (Nghiem et al, (accepted)). The inner diameter was $56.6 \mathrm{~mm}$ resulting in a was used and the stirrer speed was set at $400 \mathrm{rpm}$ to minimize polarization concentration effects. Instrument grade air was used to pressurize the stirred cell. A new membrane was used for each experiment.

Each experiment was conducted in three steps. The membrane was compacted for 1 hour using MilliQ water at 10 bar. Pure water flux was then determined at 5 bar. In the third step, the reservoir was emptied and the cell filled with the test solution. The solution was filtered at 5 bar or 10 bar for TFC-S and X-20 membranes respectively, to obtain 
compatible flux. Six permeate samples of $20 \mathrm{~mL}$ each were collected from the filtration of a feed volume of $185 \mathrm{~mL}$. A retentate sample was also collected for analysis.

\subsection{Solution Chemistry and Chemicals}

All chemicals were of analytical grade. Radiolabelled estrone-2,4,6,7- ${ }^{3} \mathrm{H}(\mathrm{N})$ was purchased from Sigma Aldrich (Saint Louis, Missouri, USA). The background electrolyte consisted of $1 \mathrm{mM} \mathrm{NaHCO}_{3}$, and $20 \mathrm{mM} \mathrm{NaCl}$. $\mathrm{pH}$ was adjusted using $1 \mathrm{M} \mathrm{HCl}$ or $1 \mathrm{M} \mathrm{NaOH}$.

\subsection{Natural Hormone Characteristics and Analysis}

Molecular structure of estrone is presented in Figure 2. Being hydrophobic, estrone has a very low solubility in water (Merck, 1996). Diameter of the molecule is estimated to be about $0.8 \mathrm{~nm}$ using Stokes-Einstein equation. The acid dissociation constant, pKa, of estrone is 10.4 (Schäfer et al., (submitted)). Hydroxyl and carbonyl functional groups of estrone can facilitate the formation of hydrogen bonding between the molecule and the membrane surface. Theoretically, estrone can be either a proton-donor or a protonacceptor species.

Feed solution was prepared by spiking estrone into background electrolyte solution to a estrone concentration of $100 \mathrm{ng} / \mathrm{L}$, which presents a typical concentration of natura hormones often encountered in water and wastewater treatment.

Estrone was analysed using a Packard Instruments scintillation counter.

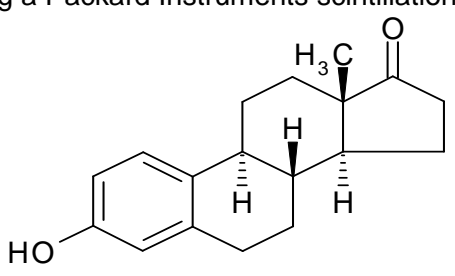

Figure 1: Molecular structure of estrone.

Adsorption of estrone to the membrane was determined by cutting the membrane into small pieces at the conclusion of each experiment. The membrane was then placed into a scintillation vial to which $5 \mathrm{~mL}$ of acetone was added. The vial was shaken vigorously and left for 1 hour for all estrone to dissolve. $1 \mathrm{~mL}$ of solution was extracted into another vial for air dry. This was redissolved with $1 \mathrm{~mL}$ of MilliQ water and added with $9 \mathrm{~mL}$ of scintillation liquid prior to analysis. Adsorption was also determined using mass balance and both methods produced similar results.

\section{Results And Discussion}

\subsection{Solute-membrane interactions}

Figure 2 shows that adsorption of estrone by TFC-S membrane drops drastically with the dissociation of estrone at $\mathrm{pH}$ 10.5. Unfortunately, the experiments do not allow differentiation between adsorption on the active layer and the support material. Hydrogen bonding was suggested as the mechanism of adsorption of estrone by the membrane (Schäfer et al, (submitted)). Hydroxyl groups are the most likely interaction sites due to aromatic groups. proton and becomes unable to participate in hydrogen bonding with membrane functiona groups, resulting in a reduction in adsorption and lower retention. Surprisingly, adsorption of estrone by $\mathrm{X}-20$ is low and remains unchanged regardless the $\mathrm{pH}$ of the matrix solution despite the fact that the membrane is also made of polyamide.

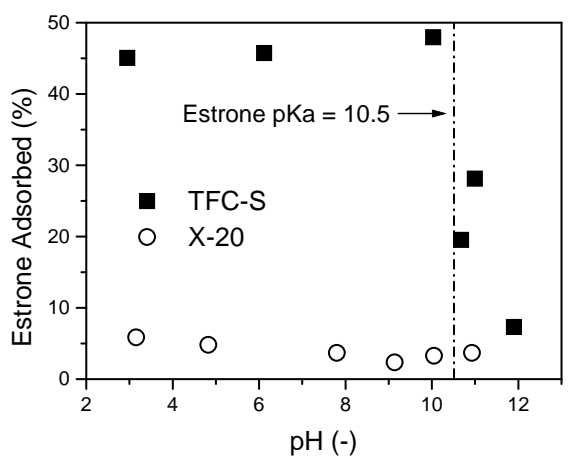

Figure 2: Estrone adsorption as a function of $\mathrm{pH}$ on TFC-S and X-20 membranes (100 $\mathrm{ng} / \mathrm{L}$ estrone; $1 \mathrm{mM} \mathrm{NaHCO}_{3} ; 20 \mathrm{mM} \mathrm{NaCl}$ ).

\subsection{Estrone retention}

Figure 3 compares estrone retention and concentration of permeates following membrane filtration by TFC-S and by X-20 at different $\mathrm{pH}$. Retention by the TFC-S membrane decreases by about $10 \%$ as $\mathrm{pH}$ exceeds pKa value of estrone (10.5) in parallel with the decreased adsorption, which was presented in Figure 2. In contrast, the estrone adsorption by the $\mathrm{X}-20$ membrane is unchanged and subsequently retention is unaffected by the $\mathrm{pH}$ of the matrix solution.

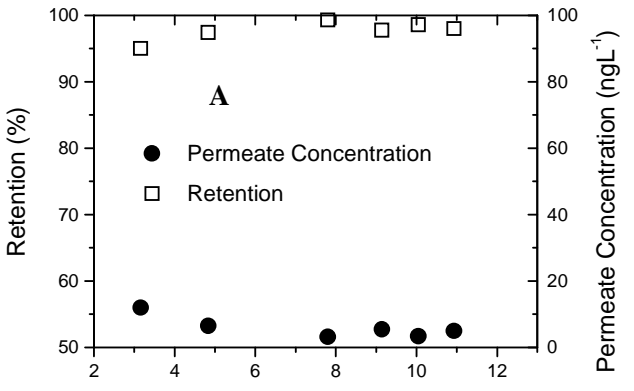

$\mathrm{pH}(-)$

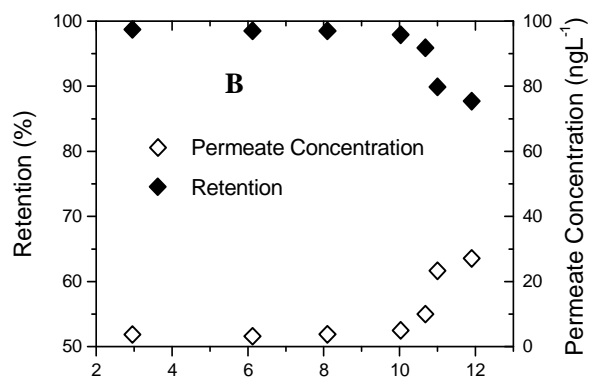

$\mathrm{pH}(-)$
Figure 3: Permeate concentration and estrone retention by $\mathrm{X}-20$ (A) and TFC-S (B) membranes as function of $\mathrm{pH}\left(100 \mathrm{ng} / \mathrm{L}\right.$ estrone; $1 \mathrm{mM} \mathrm{NaHCO}_{3}$ and $20 \mathrm{mM} \mathrm{NaCl}$ )

Mass transport of the solute across a RO membrane may involve in three major consecutive steps: (1) diffusion from the water phase into the pore of the membrane; (2) sorption onto then diffusion across the membrane; (3) desorption from the permeate side of the membrane (Chen et al., 2001). It is estimated that the molecular size of estrone is in the same order of magnitudeas the pore size of the TFC-S membrane (approximately 0.8 $\mathrm{nm}$ in diameter), while water molecules are much smaller. Transport of estrone across this membrane depends on the rate of adsorption (the formation of hydrogen bonding). Since estrone adsorption involves a more specific chemical interaction, estrone is tightly bound 
to specific sites and much less mobile than in physical adsorption. Estrone molecules are instead believed to 'hop' from one site to the next when subjected to the chemical potential across the membrane. As a result, estrone transport is retarded across the membrane layer and consequently estrone retention depends on the adsorption process. This then becomes apparent in a breakthrough curve.

It is speculated that the pore size of the $\mathrm{X}-20$ membrane is smaller than estrone molecule; thus, diffusion of estrone from the water phase into the membrane pore is not favorable. Diffusion controls the rate of estrone transfer across the membrane and sieving mechanism is mainly responsible for the separation process.

\subsection{Long term performance}

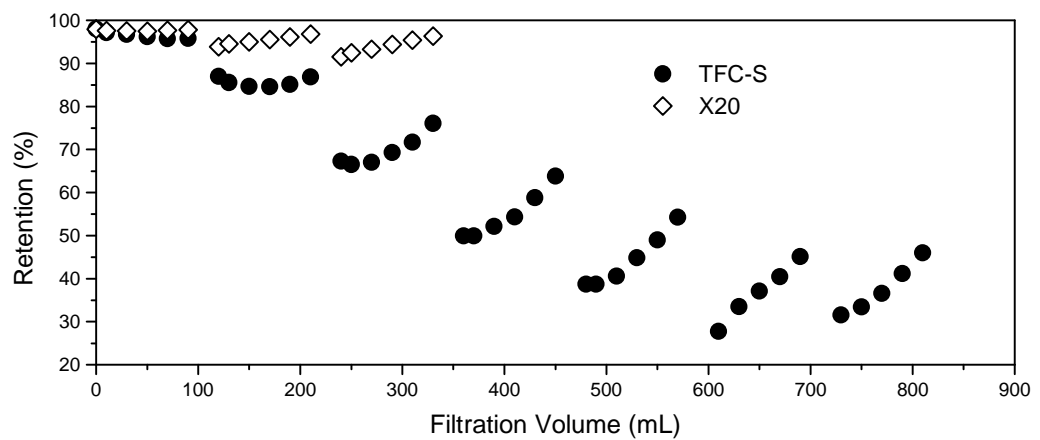

Figure 4: Retention as a function of filtration volume (100 $\mathrm{ng} / \mathrm{L}$ estrone; $1 \mathrm{mM} \mathrm{NaHCO} 3,20$ $\mathrm{mM} \mathrm{NaCl}$ and $\mathrm{pH}$ 7.8).

It appears that adsorption of trace contaminants on membranes is a temporary effect that occurs in the initial stages of filtration. While this adsorption should not be relied upon for the removal of trace contaminants, adsorption is likely to continue until the material is saturated and lead to the accumulation of large amounts of contaminants (Nghiem et al., (accepted)).

To investigate the limits of this adsorption and subsequent retention of saturated membranes, experiments were conducted with a series of fresh feed solutions for one membrane. Results from these experiments are presented in Figure 4. This indicates that the adsorption is reversible and it only slows down estrone flux across the membrane temporarily.

Not surprisingly, estrone retention by $\mathrm{X}-20$ membrane remains almost unchanged after three fresh feed solutions were filtered. A negligible reduction in retention was probably due to the operation mode of the dead end stirred cell where bulk concentration suddenly changed in the transition of a fresh feed solution to the next.

\section{Conclusions}

In this study, we investigated the adsorptive phenomena of natural hormones estrone by two RO membranes. $\mathrm{pH}$ has been found to influence the adsorption of estrone by TFC-S membranes, presumably due to hydrogen bonding, while the estrone adsorption by the X20 membrane remains unchanged. Chemical interactions between estrone and the TFC-S membrane control the rate of mass transfer of the solute across the membrane. Retention is very low when the membrane is saturated. Steric exclusion appears to be the major mechanism contributing to the removal of estrone in aqueous solution for X-20 membrane.

\section{ACKNOWLEDGEMENTS}

The Queensland Government and the Australian Research Council are thanked for project funding. We acknowledge Koch Membrane Systems (San Diego, US) and Trisep Corporation (Goleta, USA) for providing membrane samples.

\section{REFERENCES}

Chen, C., Han, B., Li, Jiding., Shang, T., Zou. J., Jiang, W. (2001). A new model on the diffusion of small molecule penetrants in dense polymer membranes. Journal of Membrane Science, 187, 109-118.

Johnson, A.C and Sumpter, J.P. (2001). Removal of Endocrine-Disrupting Chemicals in activated sludge treatment works. Environmental Science \& Technology, 35, 46974703.

Kiso, Y., Kon, T., Kitao, T., Nishimura, K. (2001). Rejection properties of alkyl phthalates with nanofiltration membranes. Journal of Membrane Science, 182, 205-214.

Kiso, Y., Nishimura, Y., Kitao, T., Nishimura, K. (2000). Rejection properties of nonphenylic pesticides with nanofiltration membranes. Journal of Membrane Science, 171, 229-237.

Merck, B.S. (1996). Merck index. $12^{\text {th }}$ Ed. Merck \& Co., Inc, New Jersey.

Nghiem, D.L., Schäfer, A.I., Waite, T.D. (2002). Membrane filtration in water recycling Removal of natural hormones, IWA $3^{\text {rd }}$ World Water Congress, Melbourne Australia April 2002 (accepted).

Schäfer, A.I., Nghiem, D.L., Waite, T.D. (2001). Removal of natural hormone estrone from Water and Wastewater using Nanofiltration and Reverse Osmosis. Environmental Science \& Technology (submitted).

Ternes, T.A., Stumpf, M., Mueller, J., Haberer, K., Wilken, R.-D., Servos, M. (1999a). Behavior and occurrence of estrogens in municipal sewage treatment plants - I. Investigations in Germany, Canada and Brazil. The Science of the Total Environment, 225, 81-90.

Ternes, T. A., Kreckel, P., Mueller, J. (1999b). Behaviour and occurrence of estrogens in municipal sewage treatment plants - II. Aerobic batch experiments with activated sludge. The Science of the Total Environment, 225, 91-99.

Wiesner, M.R and Buckley, C.A (1996). Principles of rejection in pressure driven membrane processes. In Mallevialle, J., Odendaal, P.E., Wiesner, M.R. editors, Water treatment Membrane processes. McGraw Hill, New York. 